\title{
Chemical Composition of Essential Oil from the Peel of Chinese Torreya grandis Fort
}

\author{
Tao Feng, Jian-jie Cui, Zuo-bing Xiao, Huai-xiang Tian, Feng-ping Yi, and Xia Ma \\ School of Perfume and Aroma Technology, Shanghai Institute of Technology, Shanghai 200235, China \\ Correspondence should be addressed to Tao Feng, ft422@sina.com
}

Received 1 April 2011; Revised 8 June 2011; Accepted 16 June 2011

Academic Editor: William N. Setzer

Copyright () 2011 Tao Feng et al. This is an open access article distributed under the Creative Commons Attribution License, which permits unrestricted use, distribution, and reproduction in any medium, provided the original work is properly cited.

The composition of the peel essential oil of Torreya grandis fort obtained by cold pressing and steam distillation was determined by GC and GC/MS. 62 constituents accounting for $99.6 \%$ of the total pressed oil were identified while 59 compounds accounting for $99.4 \%$ of the steam distilled oil were identified. Limonene (35.6-37.1\%), $\alpha$-pinene $(20.1-24.1 \%)$, and $\delta$-carene (3.3-3.9) were the major constituents. Others include $\gamma$-carene (3.8-3.9\%), germacrene D (2.5-2.9\%), and $\beta$-farnesene $(2.7-2.8 \%)$.

\section{Introduction}

Torreya grandis Fort. ex. Lindl is a kind of characteristic and economic tree in China, which is grown in Jiangsu, Zhejiang, Anhui, Jiangxi and Hubei province, and so on. It is a variant of Torreya cultured by people for about 1300 years and belongs to Taxaceae $[1,2]$. Torreya wood is a good material for carpentering, and it has some advantages such as a long lifetime, infertile tolerance, drought tolerance, and plant diseases and insect pests tolerance [3]. The roasted seed of Torreya is crisp, delicious, nutritious, and pharmaceutical $[4,5]$.

There is a thick layer of soft peel (also called aril) outside the seed of Torreya grandis fort, which was often abandoned and then rotten in the past. A photo of the seed of Torreya grandis fort on the tree and the micrograph picture of four wheel concentric circles arrangement of resin ducts of a transacted aril in Torreya grandis fort are shown, respectively in Figure 1. Essential oil was one of the Torreya by-products attracting keen interests of people. Now the essential oil is obtained from the peel with unique aroma like galbanum, which could be used to blend flower flavor, faint scent in the cosmetic, soap, and daily used perfume industry. Some essential oil could serve as the synthetical raw material in the chemical synthesis, and these synthetical chemicals could be used as the fine chemicals or cosmetics ingredients $[2,6]$.

Currently the yield of Torreya seed in Zhejiang province could reach 1000-1500 ton per year. However, the Torreya seed yield was only 350 ton per year before 1990s and the price was only $40-80 \mathrm{RMB}$ per kilogram; now the yield amounted up to 1000 ton per year, while the price also increased up to 100-150 RMB per kilogram, so in the long time, there is no need to worry about the price and market of Torreya seed. Therefore, the Torreya peel is also sufficient to be a raw material for extraction of its essential oil [3].

The peel of Torreya is normally discarded which consequently generated some environmental problems and hampered the development of Torreya industry. Exploring essential oil seemed to be an alternative way to evaluate the underlying economical values of Torreya due to the special roles it played in food, flavor, and cosmetics industries. With this in mind, in this paper, the chemical composition of essential oil from the peel of Torreya would be studied, in an effort to enhance the economic value of this cultivar. Concomitantly, the composition and content comparison between essential oil obtained from two methods was also made in order to determine which method would be more effective in the essential oil yielding.

\section{Experimental}

2.1. Materials. Fruits of Torreya grandis fort were donated on October 10th, 2008 by the private company of Zhaojia Town, Zhuji City, Zhejiang province.

2.2. Pretreatment of Torreya Peel. Because the Torreya peel is easy to deteriorate, it is necessary to pretreat these peels as soon as possible. In this study, two methods were adopted 


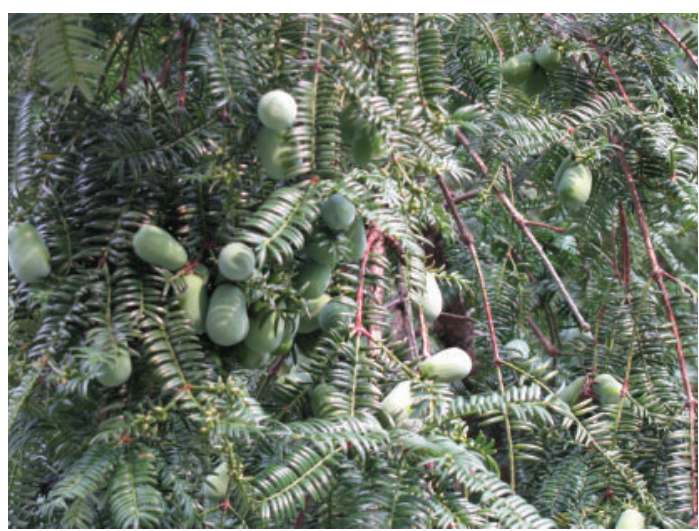

(a)

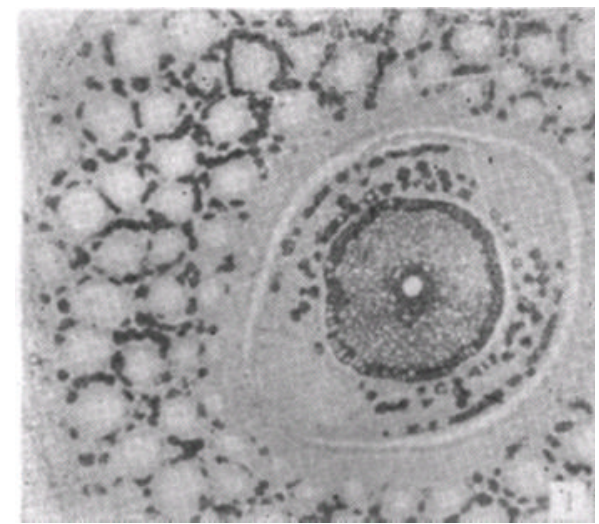

(b)

Figure 1: (a) Photo of the seed of Torreya on the tree and (b) the micrograph picture of four wheel concentric circles arrangement of resin ducts of a transacted aril in Torreya grandis.

to pretreat these peels in order to find which way is more effectively. One is cold pressing: 6 kilograms wet peels (water content about $80 \%$ ) were fed into KOMET Oil expellers (Type DD85G, IBG Monforts Oekotec GmbH \& Co., Monchengladbach, Germany) for cold pressing, and after pressing and centrifuging, the juice was stored at $0-5^{\circ} \mathrm{C}$. The other is drying: 6 kilograms wet peels (water content about $80 \%$ ) were put into electric heating air-blowing drier (104A-OS, Shanghai Jingsheng Scientific Instrument Co., Ltd., Shanghai, China) for drying at $45^{\circ} \mathrm{C}$, after that, the dried peel was crashed into powder with size from 40 mesh to 60 mesh. Finally, the powder was collected and stored in a desiccator at ambient temperature.

2.3. Extraction of Essential Oils. About $200 \mathrm{~g}$ Torreya peel powder was put in a flask supplied with $600 \mathrm{~mL}$ dd $\mathrm{H}_{2} \mathrm{O}$ plus $10 \mathrm{~g} \mathrm{NaCl}$ and subjected to steam distillation until there was no significant increase in the volume of the oil collected. After the oil volume was determined, it was dried by anhydrous $\mathrm{Na}_{2} \mathrm{SO}_{4}$ for $30 \mathrm{~min}$ and extracted by $10 \mathrm{~mL} \mathrm{CH}_{2} \mathrm{Cl}_{2}$, then concentrated under vacuum in a rotary evaporator at $40^{\circ} \mathrm{C}$ to remove the $\mathrm{CH}_{2} \mathrm{Cl}_{2}$ [7].

About $200 \mathrm{~mL}$ Torreya peel juice was put in a flask and subjected to steam distillation until there was no significant increase in the volume of the oil collected. The other procedure was the same as above.

2.4. Analysis of Essential Oils. The oil was immediately analyzed by an Agilent 7890 system equipped with a HPINNOWAX capillary column $(60 \mathrm{~m} \times 0.25 \mathrm{~mm} \times 0.25 \mu \mathrm{m})$. The analyses were carried out using helium as carrier at $1 \mathrm{~mL} / \mathrm{min}$ in a split ratio of $50: 1$ and programmed: (a) $60^{\circ} \mathrm{C}$ for $1 \mathrm{~min}$, (b) rate of $3^{\circ} \mathrm{C} / \mathrm{min}$ from 60 to $220^{\circ} \mathrm{C}$, and holding for $5 \mathrm{~min}$. The injector temperature was held at $250^{\circ} \mathrm{C}$. Injection volume was $0.2 \mu \mathrm{L}[8]$.

GC/MS analyses were carried out on the same chromatograph equipped with a Hewlett-Packard MS computerized system, Model 5975C, ionization voltage $70 \mathrm{eV}$, electron multiplier $1035 \mathrm{~V}$, ion source temperature $230^{\circ} \mathrm{C}$, quadruple rods temperature $150^{\circ} \mathrm{C}$, mass range $\mathrm{m} / \mathrm{z}$ 20-450, scanning interval $0.5 \mathrm{~s}$, and scanning speed $1000 \mathrm{amu} / \mathrm{sec}$. GC conditions were the same as above. Identification of components was based on computer matching with NIST107 and NIST21 library and comparison of the fragmentation patterns with those reported in the literatures $[9,10]$. Relative percentage amounts were calculated from total ion chromatogram (TIC) by the computer. The retention indices were calculated for all volatile constituents, using a homologous series of $n$ alkanes $\left(\mathrm{C}_{7}-\mathrm{C}_{30}\right)$ (49451-U, Sigma-Aldrich, Sigma-Aldrich (Shanghai) Trading Co., Ltd.) [10].

\section{Results and Discussion}

The oils isolated by hydrodistillation from the peel of Chinese Torreya grandis fort were found to be yellow liquids and obtained in yields of $1.25 \%(\mathrm{v} / \mathrm{w}, \mathrm{mL} / \mathrm{g})$ based on dry weights of Torreya peel and $0.5 \%(\mathrm{v} / \mathrm{w}, \mathrm{mL} / \mathrm{g})$ based on wet weights of Torreya peel, respectively.

Two methods for extracting the essential oil from the peel of Torreya grandis fort were compared in this paper, and it was found that, in the reported 62 and 59 compounds of the essential oil according to steam distillation and cold pressing, there was a large similarity between these reported compounds from essential oil by two different methods. 62 and 59 compounds with $99.6 \%$ and $99.4 \%$ of total areas were identified, respectively, using both chromatographic (retention indices) and spectroscopic (mass spectra) criteria. That is to say, 65 compounds were totally identified from essential oils by both methods. The major components were found to be limonene (37.06\% and $35.63 \%), \alpha$-pinene $(20.13 \%$ and $24.11 \%), \delta$-cadinene $(4.82 \%$ and $4.24 \%), 3-$ carene $(3.92 \%$ and $3.81 \%)$, germacrene $\mathrm{D}(2.9 \%$ and $2.46 \%)$, and $\beta$-farnesene $(2.78 \%$ and $2.68 \%)$ by cold pressing and warm drying treatment, respectively.

Chemical composition of the Chinese Torreya grandis fort oils can be seen in Table 1. The components are listed in the order of their elution on the HP-INNOWAX column.

Comparison of the oil composition by two treatments of the peel showed that the amounts of the main and some 
TABle 1: Percentage composition of the oils of Chinese Torreya grandis Fort.

\begin{tabular}{|c|c|c|c|c|c|c|}
\hline \multirow{3}{*}{ No. } & \multirow{3}{*}{ Compound } & \multirow{3}{*}{$\mathrm{RI}^{\mathrm{a}}$} & \multicolumn{3}{|c|}{ Pretreatment method } & \multirow{3}{*}{ Method of identification } \\
\hline & & & \multirow{2}{*}{ Standard $\mathrm{RI}^{\mathrm{b}}$} & \multicolumn{2}{|c|}{ Mass percentage $\%$} & \\
\hline & & & & Cold pressing & Warm drying & \\
\hline 1 & Tricyclen & 1018 & 1014 & 0.2 & 0.2 & $\mathrm{MS}^{\mathrm{c}}, \mathrm{RI}$ \\
\hline 2 & $\alpha$-Pinene & 1037 & 1026 & 20.1 & 24.1 & MS, RI \\
\hline 3 & Fenchene & 1068 & 1045 & 0.3 & 0.3 & MS, RI \\
\hline 4 & Camphene & 1077 & 1076 & 0.7 & 0.8 & MS, RI \\
\hline 5 & $\beta$-Pinene & 1117 & 1115 & 2.4 & 2.5 & MS, RI \\
\hline 6 & Sabinene & 1130 & 1132 & 0.9 & 0.5 & MS, RI \\
\hline 7 & $\gamma$-Carene & 1159 & 1148 & 3.9 & 3.8 & MS, RI \\
\hline 8 & $\beta$-Myrcene & 1170 & 1160 & 3.6 & 3.3 & MS, RI \\
\hline 9 & Limonene & 1212 & 1218 & 37.1 & 35.6 & MS, RI \\
\hline 10 & $\beta$-phellandrene & 1218 & 1210 & 0.8 & 0.7 & MS, RI \\
\hline 11 & cis-Ocimene & 1241 & 1223 & 0.2 & 0.1 & MS, RI \\
\hline 12 & trans- $\beta$-Ocimene & 1258 & 1235 & 0.2 & 0.1 & MS, RI \\
\hline 13 & p-cymene & 1278 & 1261 & 0.3 & 0.4 & MS, RI \\
\hline 14 & $\alpha$-Terpinolene & 1288 & 1278 & 0.4 & 0.3 & MS, RI \\
\hline 15 & Isoterpinolene & 1380 & 1390 & - & 0.1 & MS, RI \\
\hline 16 & o-Allyltoluene & 1442 & & 0.1 & 0.1 & MS \\
\hline 17 & cis-Limonene oxide & 1450 & & - & 0.1 & MS \\
\hline 18 & $\alpha$-Cubebene & 1462 & 1468 & 0.3 & 0.5 & MS, RI \\
\hline 19 & $\delta$-Elemene & 1474 & 1479 & - & 0.1 & MS, RI \\
\hline 20 & $\alpha$-Copaene & 1495 & 1497 & 0.1 & 0.1 & MS, RI \\
\hline 21 & Methyl pulegenate & 1499 & & 0.1 & - & MS \\
\hline 22 & $\alpha$-Gurjunene & 1535 & 1544 & 0.1 & 0.1 & MS, RI \\
\hline 23 & $\beta$-Cubebene & 1542 & 1543 & 0.5 & 0.3 & MS, RI \\
\hline 24 & Bornyl acetate & 1582 & 1570 & 0.2 & 0.1 & MS, RI \\
\hline 25 & $\beta$-Elemene & 1592 & 1578 & 0.2 & 0.2 & MS, RI \\
\hline 26 & Epi-bicyclosesquiphellandrene & 1595 & 1638 & 1.0 & 0.9 & MS, RI \\
\hline 27 & caryophyllene oxide & 1601 & 1579 & 1.1 & 1.0 & MS, RI \\
\hline 28 & Aromadendrene & 1611 & 1609 & 0.1 & 0.17 & MS, RI \\
\hline 29 & trans-p-Mentha-2,8-dien-1-ol & 1626 & & 0.2 & 0.2 & MS \\
\hline 30 & $\gamma$-Elemene & 1641 & 1651 & 0.1 & 0.1 & MS, RI \\
\hline 31 & cis-Verbenol & 1654 & 1663 & 0.1 & - & MS, RI \\
\hline 32 & trans- $\beta$-Farnesene & 1667 & 1662 & 2.8 & 2.7 & MS, RI \\
\hline 33 & $\alpha$-Humulene & 1675 & 1662 & 0.6 & 0.8 & MS, RI \\
\hline 34 & 1,8-menthadien-4-ol & 1685 & & 0.1 & 0.1 & MS \\
\hline 35 & $\gamma$-Muurolene & 1692 & 1706 & 0.7 & 1 & MS, RI \\
\hline 36 & $\alpha$-Terpineol & 1694 & 1706 & 0.4 & 0.3 & MS, RI \\
\hline 37 & $\alpha$-Terpinenyl acetate & 1696 & & 0.3 & 0.3 & MS \\
\hline 38 & Isoborneol & 1698 & 1664 & 0.4 & 0.3 & MS, RI \\
\hline 30 & Verbenone & 1709 & 1733 & 0.1 & 0.1 & MS, RI \\
\hline 40 & Germacrene D & 1714 & 1721 & 2.9 & 2.5 & MS, RI \\
\hline 41 & $\begin{array}{l}\text { 2-Isopropyl-5-methyl-9- } \\
\text { methylene-bicyclo[4.4.0] dec-1-ene }\end{array}$ & 1719 & & 1.0 & 1.1 & MS \\
\hline 42 & $\beta$-Selinene & 1724 & 1618 & 0.4 & 0.3 & MS, RI \\
\hline 43 & $\alpha$-amorphene & 1728 & & 1.8 & 1.7 & MS \\
\hline 44 & Carvone & 1737 & 1751 & 0.4 & - & MS, RI \\
\hline 45 & 1-Decanol & 1756 & 1752 & 0.2 & 0.1 & MS, RI \\
\hline 46 & $\gamma$-Cadinene & 1762 & 1765 & 4.8 & 4.2 & MS, RI \\
\hline
\end{tabular}


TABle 1: Continued.

\begin{tabular}{|c|c|c|c|c|c|c|}
\hline \multirow{3}{*}{ No. } & \multirow{3}{*}{ Compound } & \multirow{3}{*}{$\mathrm{RI}^{\mathrm{a}}$} & \multicolumn{3}{|c|}{ Pretreatment method } & \multirow{3}{*}{ Method of identification } \\
\hline & & & \multirow{2}{*}{ Standard $\mathrm{RI}^{\mathrm{b}}$} & \multicolumn{2}{|c|}{ Mass percentage $\%$} & \\
\hline & & & & Cold pressing & Warm drying & \\
\hline 47 & $\delta$-Cadinene & 1764 & 1772 & 0.1 & 0.3 & MS, RI \\
\hline 48 & trans-Carveol & 1832 & 1836 & 0.4 & 0.3 & MS, RI \\
\hline 49 & Germacrene B & 1834 & 1811 & 0.1 & 0.1 & MS, RI \\
\hline 50 & Calamenene & 1837 & 1816 & 1.2 & 1.4 & MS, RI \\
\hline 51 & p-Cymen-8-ol & 1847 & 1834 & 0.3 & 0.3 & MS, RI \\
\hline 52 & cis-Carveol & 1863 & 1861 & 0.2 & 0.2 & MS, RI \\
\hline 53 & $\alpha$-Calacorene & 1920 & 1912 & 0.1 & - & MS, RI \\
\hline 55 & Palustrol & 1931 & 1956 & 0.1 & 0.2 & MS, RI \\
\hline 56 & (Z)-3-Decen-1-ol & 1983 & & 0.1 & - & MS \\
\hline 57 & Caryophyllene oxide & 1987 & 1947 & 0.2 & 0.2 & MS, RI \\
\hline 58 & Humulene epoxide II & 2045 & 2002 & 0.1 & - & MS, RI \\
\hline 59 & Germacrene D-4-ol & 2050 & 2057 & 0.1 & 0.1 & MS, RI \\
\hline 60 & Spathulenol & 2123 & 2144 & 1.9 & 1.7 & MS, RI \\
\hline 61 & $\begin{array}{l}\text { 2-isopropyl-5-methyl-9- } \\
\text { methylene-Bicyclo[4.4.0] dec-1-ene }\end{array}$ & 2170 & & 0.1 & 0.1 & MSI \\
\hline 62 & t-Muurolol & 2185 & 2187 & 0.2 & 0.1 & MS, RI \\
\hline 63 & 6-cadinol & 2197 & & 1.8 & 1.9 & MS \\
\hline 64 & Isospathulenol & 2224 & 2225 & 0.1 & 0.1 & MS, RI \\
\hline \multirow[t]{2}{*}{65} & $\alpha$-Cadinol & 2231 & 2235 & 0.3 & 0.1 & MS, RI \\
\hline & total & & & 99.6 & 99.4 & \\
\hline
\end{tabular}

${ }^{a}$ RI: retention indices in elution order from HP-INNOWAX column.

${ }^{b}$ RI Standard: these data all are published.

${ }^{\mathrm{c}}$ MS: mass spectroscopy.

minor components are different in the oils by cold pressing treatment $(\mathrm{CPT})$ and warm drying treatment (WDT); for example, the content of limonene of the CPT oil (37.06\%) is higher than that of WDT oil (35.63\%), while the CPT oil contains $\alpha$-Pinene $(20.13 \%)$ in relatively lower amount than WDT oil does $(24.11 \%)$. The contents of $\delta$-Cadinene and 3Carene are higher in CPT oil. Some minor components, such as cis-verbenol, carvone, para-cymen-8-ol, $\alpha$-calacorene, Caryophyllene oxide, Perilla alcohol, humulene epoxide II, cadalin, were found only in CPT oil, while $\alpha$-pinene oxide, cis-limonene oxide, 2-methylenebicyclo[2.1.1] hexane, $\delta$ elemene and were only found in WDT oil.

In the essential oil herein, such constitutes as limonene, $\alpha$-pinene, $\beta$-pinene, and germacrene $\mathrm{D}$ exhibited typical flavors [7]. Limonene exhibited a fresh, light, and sweet odor. Germacrene D possessed a warm-spicy-woody flavor. The odors of $\alpha$-pinene and $\beta$-pinene were warm-resinous, refreshing pinelike. Therefore, the essential oil of Chinese Torreya grandis fort constitutes may be valuable for the flavoring of foods, where floral-fresh-fruity aromas are required, such as chewing gums, sweets, teas, soft and energy drinks as well as milk products. In cosmetics, the investigated essential oil with characteristic floral-fresh-fruity odor impressions may be used in shampoos, soaps, shower gels, body lotions, and tooth pastes, while an application of the oils in fine perfumery seems to be interesting as top notes in perfumes and deodorants. It could also be used in the food preservation due to high percentage of well-known antimicrobial compounds with the $\alpha$-pinene, $\beta$-pinene, and limonene [11-16].

\section{Acknowledgments}

This work was supported by Shanghai Natural Science Fund (09ZR1431400) and also supported by National Natural Science Fund (31000794).

\section{References}

[1] X. Y. Yu, P. Li, X. Y. Dong et al., "Aril Structure and Its Aromatic Oil in Torreya grandis Fort. ex Lindl," Journal of Hangzhou University (Natural Science Edition), vol. 13, no. 3, pp. 347-351, 1986.

[2] M. K. Saeed, Y. Deng, Z. Parveen, R. Dai, W. Ahmad, and Y. $\mathrm{Yu}$, "Studies on the chemical constituents of Torreya grandis Fort. Ex Lindl," Journal of Applied Sciences, vol. 7, no. 2, pp. 269-273, 2007.

[3] B. Galli, F. Gasparrini, V. Lanzotti et al., "Grandione, a new heptacyclic dimeric diterpene from Torreya grandis Fort," Tetrahedron, vol. 55, no. 37, pp. 11385-11394, 1999.

[4] X. F. Shi and X. N. Yuan, "Physical and chemical analysis of ths seed of Torreya grandis Fort," Journal of Fujian Forestry Colledge, vol. 9, no. 1, pp. 85-88, 1989. 
[5] B.-Q. Chen, X.-Y. Cui, X. Zhao et al., "Antioxidative and acute antiinflammatory effects of Torreya grandis," Fitoterapia, vol. 77, no. 4, pp. 262-267, 2006.

[6] Y. Minari, A. Fukumoto, N. Tokui, X. Guo, G. S. Zhu, and F. Uchiyama, Characteristics of Chinese Health Foods and Planning for Healthy Diet, VIII International People-Plant Symposium on Exploring Therapeutic Powers of Flowers, Greenery and Nature, ISHS Press, Leuven, Belgium, 2005.

[7] C.-C. Chyau, S.-Y. Tsai, J.-H. Yang et al., "The essential oil of Glossogyne tenuifolia," Food Chemistry, vol. 100, no. 2, pp. 808-812, 2007.

[8] C. K. Shu, B. M. Lawrence, and E. M. Croom Jr., "Essential oil of Torreya taxifolia Arnott," Journal of Essential Oil Research, vol. 7, no. 1, pp. 71-72, 1995.

[9] F. Sefidkon and R. Kalvandi, "Chemical composition of the essential oil of Micromeria persica Boiss. from Iran," Flavour and Fragrance Journal, vol. 20, no. 5, pp. 539-541, 2005.

[10] F. Sefidkon and R. Kalvandi, "Essential oil analysis of Iranian Satureja edmondi and S. isophylla," Flavor and Fragrance Journal, vol. 21, no. 2, pp. 230-233, 2006.

[11] D. R. L. Caccioni, M. Guizzardi, D. M. Biondi, A. Renda, and G. Ruberto, "Relationship between volatile components of citrus fruit essential oils and antimicrobial action on Penicillium digitatum and Penicillium italicum," International Journal of Food Microbiology, vol. 43, no. 1-2, pp. 73-79, 1998.

[12] L. R. Williams, J. K. Stockley, W. Yan, and V. N. Home, "Essential oils with high antimicrobial activity for therapeutic use," International Journal of Aromatherapy, vol. 8, no. 4, pp. 30-39, 1998.

[13] N. Filipowicz, M. Kamiński, J. Kurlenda, M. Asztemborska, and J. R. Ochocka, "Antibacterial and antifungal activity of juniper berry oil and its selected components," Phytotherapy Research, vol. 17, no. 3, pp. 227-231, 2003.

[14] A. Cakir, S. Kordali, H. Zengin, S. Izumi, and T. Hirata, "Composition and antifungal activity of essential oils isolated from Hypericum hyssopifolium and Hypericum heterophyllum," Flavour and Fragrance Journal, vol. 19, no. 1, pp. 62-68, 2004.

[15] M. L. Magwa, M. Gundidza, N. Gweru, and G. Humphrey, "Chemical composition and biological activities of essential oil from the leaves of Sesuvium portulacastrum," Journal of Ethnopharmacology, vol. 103, no. 1, pp. 85-89, 2006.

[16] V. K. Bajpai, A. Rahman, and S. C. Kang, "Chemical composition and anti-fungal properties of the essential oil and crude extracts of Metasequoia glyptostroboides Miki ex Hu," Industrial Crops and Products, vol. 26, no. 1, pp. 28-35, 2007. 


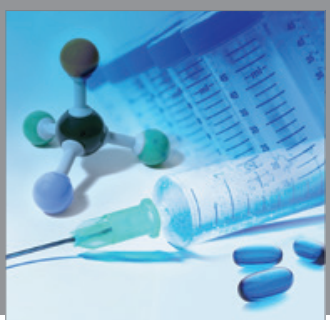

International Journal of

Medicinal Chemistry

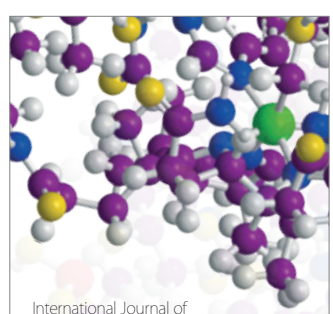

Carbohydrate Chemistry

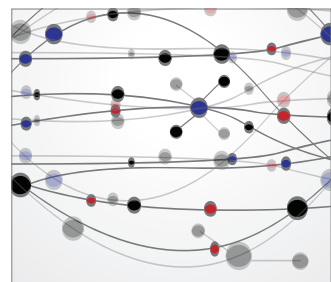

The Scientific World Journal
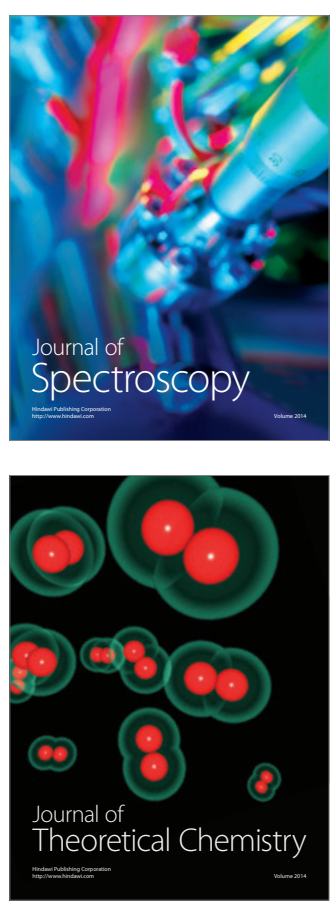
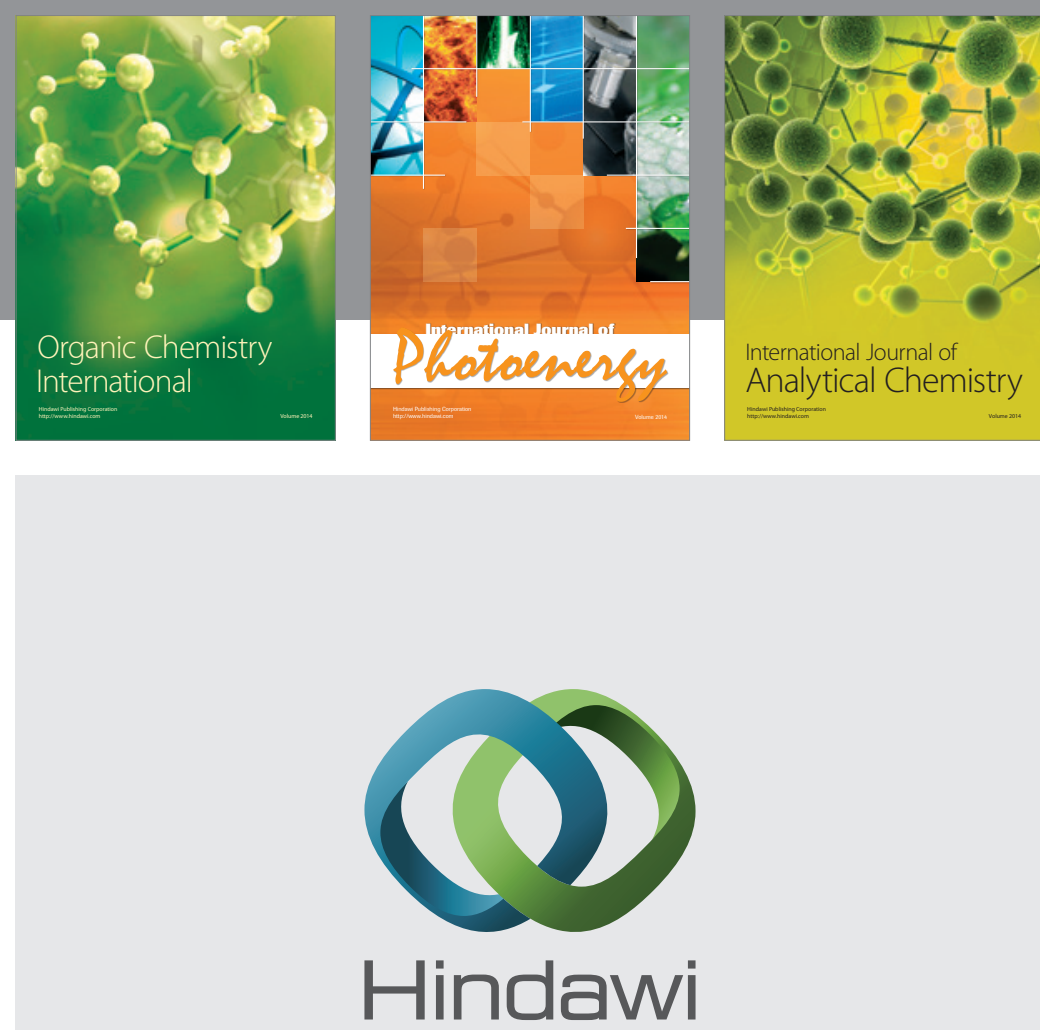

Submit your manuscripts at

http://www.hindawi.com
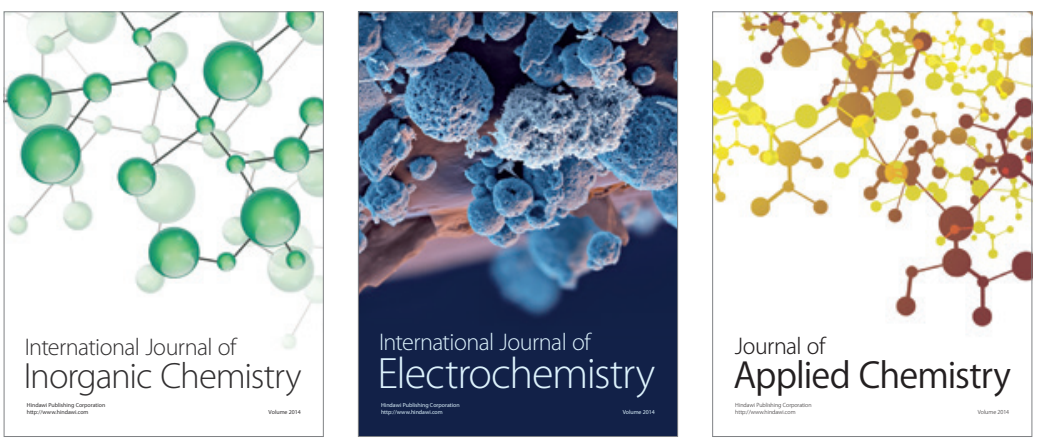

Journal of

Applied Chemistry
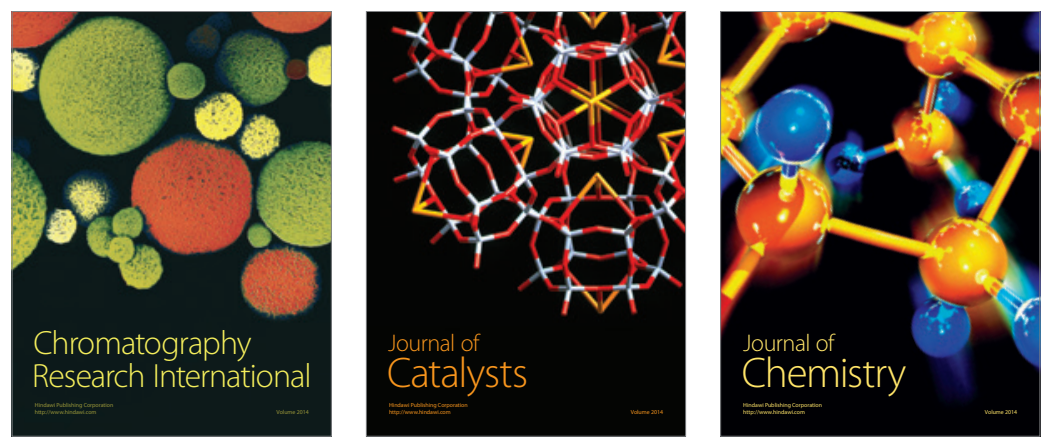
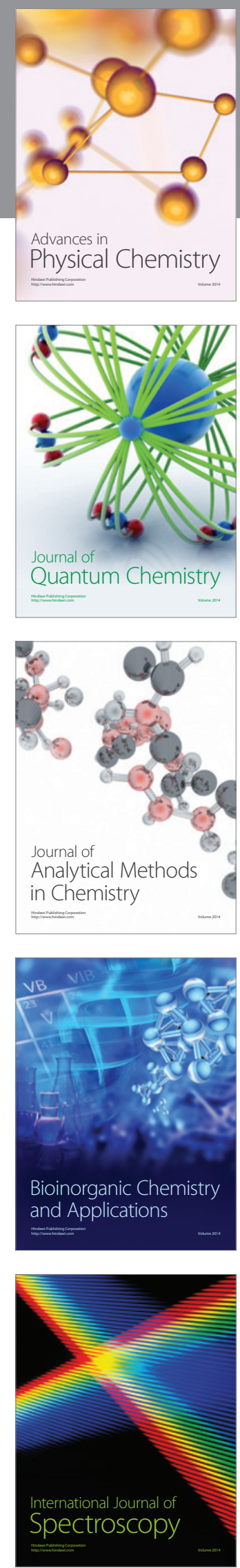